\title{
Evaluasi Kinerja Sistem Elektrokoagulasi Batch Recycle Dengan Susunan Eleltroda Monopolar Dalam Mengolah Limbah Cair Tapioka
}

\author{
Lilis Hermida $^{1}$, Ika Kustiani ${ }^{2}$, Suharno ${ }^{3}$ \\ ${ }^{1)}$ Program Profesi Insinyur, Universitas Lampung \\ ${ }^{2)}$ Teknik Sipil, Fakultas Teknik, Universitas Lampung \\ ${ }^{3)}$ Teknik Geofisika, Fakultas Teknik, Universitas Lampung \\ J1. Prof. Sumantri Brojonegoro No.1 Bandar Lampung 35145 \\ Corresponding author: lilis.hermidadeng.unila.ac.id
}

Intisari - Pada penelitian ini elektrokoagulasi limbah cair tapioka dilakukan di reaktor yang beroperasi secara batch recycle, yang menggunakan beberapa pasang elektroda dalam susunan monopolar. Pengaruh variasi parameter operasi (besarnya arus listrik, jarak antar elektroda dan konduktivitas limbah cair tapioka) terhadap persentase penurunan kekeruhan air limbah diamati. Kemudian kondisi operasi yang optimal di investigasi menggunakan rancangan percobaan fractional factorial taguchi. Berdasarkan hasil percobaan dapat disimpulkan bahwa arus listrik sangat mempengaruhi persentase penurunan kekeruhan limbah cair tapioka. Kenaikan pH limbah terjadi selama proses berlangsung. Dengan pH influent tetap pada 7, setelah waktu reaksi selama 5 jam pH effluent menjadi 9,4 -9,6. Kondisi optimum diperoleh pada arus listrik 0,4 A, jarak antar elektroda 1,5 cm, dan konduktivitas influent $2500 \mathrm{mS}$ dengan pH 7, laju alir 9 1/jam dan waktu pengolahan 5 jam. Persentase penurunan kekeruhan pada kondisi optimum bisa mencapai 97,227\%.

Kata kunci - Elektrocoagulasi, Sistem batch recycle, Elektroda aluminium, Susunan monopolar, Limbah cair tapioka

Abstract - In this study electrocoagulation of tapioca waste water was carried out in a reactor with batch recycle mode using several aluminium electrodes in monopolar arrangement. Effects of various factors (electrical current, distance between electrodes, conductivity of the waste water) to turbidity removal were observed. Optimum operating conditions were investigated using experimental design of taguchi fractional factorial. Based on experimental results it can be concluded that electrical current had the highest effect to turbidity removal of tapioca waste water. The $\mathrm{pH}$ increased with the increase in reaction time in the process. pH of influent was maintained at 7, after reaction time of $5 \mathrm{~h} \mathrm{pH}$ of effluent became at around 9.4- 9.6. Optimum condition was found at electrical current of $0.4 \mathrm{~A}$, electrode distance of $1.5 \mathrm{~cm}$, influent conductivity of $2500 \mathrm{mS}$, pH 7, flow rate of 9 1/hour and reationtime of 5 hour. Removal of turbidity at optimum condition reached $97.227 \%$

Keywords - Electrocoagulation, batch recycle sistem, aluminum electrode, monopolar arragement, tapioca waste water

\section{PENDAHULUAN}

Propinsi Lampung merupakan salah satu sentra industri tapioka di Indonesia. Hingga tahun 1998 di propinsi tersebut terdapat sekitar 60 industri tapioka berskala menengah dan besar, serta puluhan industri berskala kecil yang tergabung dalam kelompok Ittara (Industri tepung tapioka rakyat) [1]. Zat tapioka sangat dibutuhkan berbagai industri seperti pada industri makanan, farmasi, tekstil, kertas, dan perekat. Dalam proses produksinya, industri tapioka berpotensi menyebabkan pencemaran lingkungan karena buangan padat dan cair dari proses pengolahan singkong. Limbah cair merupakan buangan yang paling banyak dihasilkan karena pengolahan singkong 
menjadi tapioka menghasilkan sekitar 4.0006.000 liter limbah cair per ton bahan baku [2].

Limbah cair industri tapioka memiliki kandungan zat organik yang tinggi [3,4]. Zat tersebut apabila terdegradasi secara alami mengakibatkan limbah cair menjadi keruh dan berwarna coklat kehitam-hitaman [5]. Limbah cair tapioka memiliki tingkat kekeruhan yang sangat tinggi yaitu 1.400 NTU dengan $\mathrm{pH}$ antara 4,0-6,5, kandungan COD dan BOD sekitar 7.000-30.000 miligram per liter dan 3.000-7.500 miligram per liter [6]. Dengan karakteristik tersebut, limbah cair tapioka jika tidak diolah akan memberikan dampak yang kurang baik bagi lingkungan. Dampak limbah cair industri tapioka mendapat perhatian yang serius dari Pemerintah Propinsi Lampung sejak tahun 1990 [7].

Penghilangan kandungan zat padat dengan cara koagulasi dan sedimentasi menerapkan penggunaan bahan-bahan kimia, sehingga dibutuhkan proses sekunder untuk menetralisasi kelebihan bahan kimia yang digunakan $[8,9]$. Pengolahan biologi untuk penurunan kandungan BOD dan COD cairan cenderung berlangsung lambat dan sangat spesifik [10]. Sedangkan proses adsorpsi dan filtrasi sangat bergantung dengan luas permukaan kontak yang cenderung berkurang selama proses pengolahan beroperasi $[11,12]$.

Proses elektrokoagulasi merupakan suatu proses yang efektif untuk mendestabilisasi partikel-partikel halus yang terdispersi didalam limbah cair dan persenyawaan organik kompleks [13]. Dengan proses tersebut, partikel-partikel zat padat mengumpul membentuk flok-flok. Pada saat yang hampir bersamaan, gelembung-gelembung kecil gas hidrogen yang dihasilkan didaerah katoda dapat mengapungkan flok yang terbentuk sehingga menambah keefektifan pemisahan flok-flok dari limbah.

\section{Dibalik pengoperasian sistem} elektrokoagulasi yang sederhana (pada dasarnya terdiri dari pipa, pompa,dan sumber arus DC) terdapat reaksi rumit yang terjadi didalam proses tersebut [14]. Ketika sistem elektrokoagulasi beroperasi, air limbah yang mengandung partikel koloid dan kontaminankontaminan lain akan dialirkan menuju suatu medan listrik, sehingga daya ionisasi, elektrolisa, hidrolisa, pembentukan radikal bebas, dan kemagnetan merubah sifat-sifat kimia dan fisika daripada air dan kontaminankontaminan tersebut. Keadaan reaktif seperti ini menyebabkan kontaminan terlepas dari air. Dalam waktu yang singkat, campuran airkontaminan terpisah menjadi lapisan organik yang mengapung dan air jernih yang kemudian dengan mudah dapat dipisahkan dengan metoda pemisahan konvensional.

Chen dkk [15] menguraikan bahwa variabel operasional $(\mathrm{pH}$, konduktifitas air limbah, voltase elektrolisa, jenis elektroda, dan beban muatan listrik) mempengaruhi unjuk kerja sistem elektrokoagulasi, dan menyimpulkan bahwa beban muatan listrik merupakan variabel yang paling menentukan. Faktor lain yang harus dipertimbangkan terhadap keberhasilan kinerja sistem adalah konfigurasi reaktor elektrokoagulasi [16]. Berdasarkan penjelasan diatas maka dipandang perlu untuk melakukan serangkaian penelitian elektrokoagulasi limbah cair tapioka dengan menggunakan reaktor elektrokoagulasi yang beroperasi secara batch recycle, yang menggunakan beberapa pasang elektroda yang disusun secara monopolar dan yang dilengkapi dengan unit pemisahan flok. Variasi parameter operasi (besarnya arus, jarak antar elektroda serta konduktivitas dan $\mathrm{pH}$ limbah cair tapioka) diterapkan untuk mengetahui pengaruhnya terhadap tingkat penurunan kekeruhan. Kondisi operasi yang optimal diinvestigasi dengan menggunakan rencangan percobaan fraksional factorial taguchi sehingga diperoleh tingkat penurunan kekeruhan paling tinggi

\section{BAHAN DAN ALAT PENELITIAN}

Bahan-bahan yang digunakan dalam penelitian ini adalah : Limbah cair pabrik tapioka milik BPPT di Sulusuban -Lampung Tengah, $\mathrm{NaCl}$, Air suling, Elektroda $\mathrm{Al}, \mathrm{pH}$ meter, gelas ukur, vial, turbidimeter OrbecoHellige, alat elektrokoagulasi yang dipabrikasi yang dilengkapi dengan DC power supply, pipa, selang, pompa dan keran.

III. METODA PENELITIAN 
Sistem operasi peralatan pada penelitian ini berlangsung secara batch recycle seperti uang diilustrasikan pada Gambar 1. keadaan awal limbah cair tapioka yang diambil dari industri tapioka dianalisis terlebih dahulu yang meliputi analisis pH dan kekeruhan (NTU / Nephelometric Turbidity Unit) kemudian dilakukan penetapan kondisi operasi percobaan berdasarkan rancangan percobaan frasional faktorial taguchi seperti pada Tabel 1 .

Pada percobaan pertama yaitu pada kondisi operasi : kuat arus 0,2 A, konduktivitas influent $2000 \mu \mathrm{s} / \mathrm{cm}$, dan jarak antar elektroda $0,5 \mathrm{~cm}$ dilakukan dengan langkah-langkah sebagai berikut :

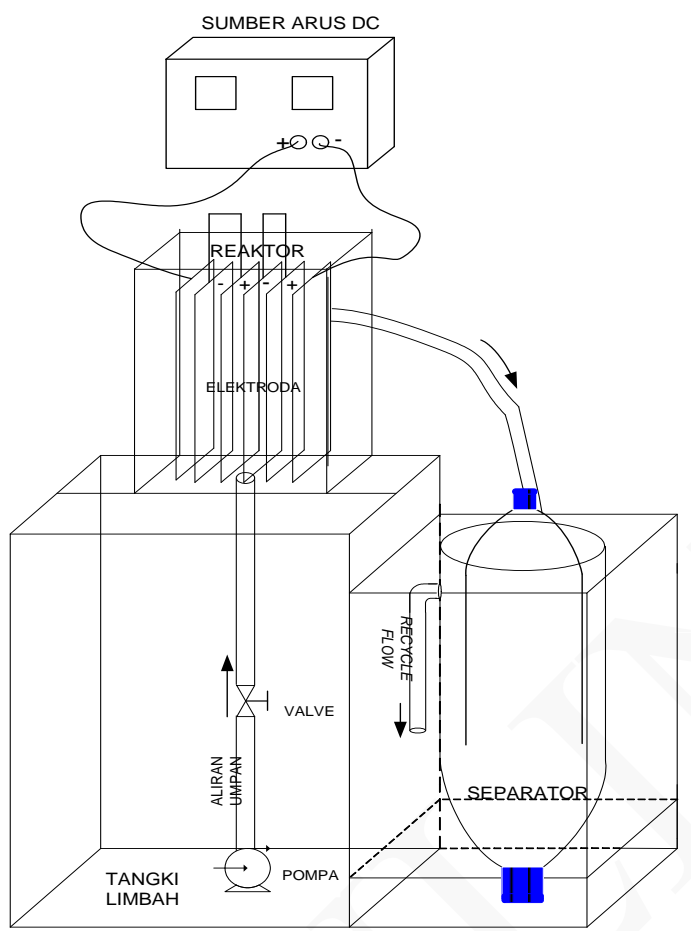

Gambar 1. Alat Elektrokoagulasi

Tabel 1. Rancangan Percobaan fraksional factorial Taguchi

\begin{tabular}{|c|c|c|c|}
\hline Run & $\begin{array}{c}\text { Arus } \\
(\mathrm{A})\end{array}$ & $\begin{array}{c}\text { Konduk } \\
\text { tivitas } \\
(\mu \mathrm{s} / \mathrm{cm})\end{array}$ & $\begin{array}{c}\text { Jarak antar } \\
\text { elektroda } \\
(\mathrm{cm})\end{array}$ \\
\hline 1 & 0,2 & 2000 & 0,5 \\
\hline 2 & 0,2 & 2250 & 1,0 \\
\hline 3 & 0,2 & 2500 & 1,5 \\
\hline 4 & 0,3 & 2000 & 1,0 \\
\hline 5 & 0,3 & 2250 & 1,5 \\
\hline
\end{tabular}

\begin{tabular}{|c|c|c|c|}
\hline 6 & 0,3 & 2500 & 0,5 \\
\hline 7 & 0,4 & 2000 & 1,5 \\
\hline 8 & 0,4 & 2250 & 0,5 \\
\hline 9 & 0,4 & 2500 & 1,0 \\
\hline
\end{tabular}

Limbah cair tapioka diambil sebanyak 3 liter ditempatkan di dalam tangki influent yang dilengkapi dengan pengaduk magnetik kemudian dilakukan pengaturan $\mathrm{pH}$ sehingga limbah tapioka tersebut mempunyai $\mathrm{pH}=7$ dengan cara menambahkan $\mathrm{NaOH}$ ke dalam limbah tersebut sambil dianalisis pH-nya.. Konduktivitas air limbah diukur dengan alat konduktivitas meter. Air limbah tersebut kemudian dikondisikan agar konduktivitasnya $2000 \mu \mathrm{s} / \mathrm{cm}$ dengan cara menambahkan larutan garam $(\mathrm{NaCl})$ ke dalam limbah tersebut sedikit demi sedikit sambil diatur konduktivitasnya.

Reaktor elektrokoagulasi disiapkan dengan memasang dan mengatur enam elektroda alumunium pada tempatnya dengan jarak antar elektroda 0,5 cm. Pompa dihidupkan untuk mensirkulasi limbah cair tapioka melalui sistem peralatan elektrokoagulasi (Gambar 1) selama beberapa menit untuk memastikan tidak adanya kebocoran. Laju alir diatur sebesar 150 $\mathrm{ml} / \mathrm{menit}$. Laju alir yang dipakai adalah tetap untuk setiap percobaan. Sistem dibiarkan berjalan selama beberapa menit sampai laju alir konstan. Percobaan dimulai ketika reaktor elektrokoagulasi dihubungkan dengan sumber arus DC dengan arus sebesar 0,2 A.

Percobaan (Run) kedua sampai percobaan kesembilan dilakukan tahapan-tahapan

seperti pada percobaan pertama diatas dengan kondisi operasi yang ditetapkan berdasarkan desain percobaan pada Tabel 1.

Untuk mengetahui kinerja kerja reaktor, setiap interval waktu 1 jam dilakukan pengambilan sampel sebanyak $30 \mathrm{ml}$ untuk analisa $\mathrm{pH}$ dan kekeruhannya (NTU). Pada jam ke lima proses diakhiri dengan cara mematikan sumber listrik DC. Kemudian sampel diambil untuk dianalisis.

Tabel 2. Data Hasil Penelitian 


\begin{tabular}{|c|c|c|c|c|c|c|c|}
\hline \multirow{2}{*}{ Run } & Jam & $\mathbf{0}$ & $\mathbf{1}$ & $\mathbf{2}$ & $\mathbf{3}$ & $\mathbf{4}$ & $\mathbf{5}$ \\
\hline \multirow{4}{*}{1} & $\mathrm{NTU}$ & 306 & 261 & 168 & 108 & 58 & 27 \\
\cline { 2 - 8 } & $\%$ & 0 & 14,706 & 45,098 & 64,706 & 81,046 & 91,176 \\
\cline { 2 - 8 } & $\mathrm{pH}$ & 7 & 8.1 & 8.2 & 9.1 & 9.3 & 9.5 \\
\hline \multirow{4}{*}{2} & $\mathrm{NTU}$ & 191 & 150 & 78 & 54 & 27 & 17 \\
\cline { 2 - 8 } & $\%$ & 0 & 21,466 & 59,162 & 71,728 & 85,864 & 91,099 \\
\cline { 2 - 8 } & $\mathrm{pH}$ & 7 & 7.8 & 9.1 & 8.3 & 9.5 & 9.5 \\
\hline \multirow{4}{*}{3} & $\mathrm{NTU}$ & 329 & 254 & 152 & 88 & 42 & 20 \\
\cline { 2 - 8 } & $\%$ & 0 & 22,796 & 53,799 & 73,252 & 87,234 & 93,921 \\
\cline { 2 - 8 } & $\mathrm{pH}$ & 7 & 8.3 & 9.1 & 9.4 & 9.6 & 9.6 \\
\hline \multirow{4}{*}{4} & $\mathrm{NTU}$ & 270 & 201 & 120 & 56 & 34 & 17 \\
\cline { 2 - 8 } & $\%$ & 0 & 25,556 & 55,556 & 79,259 & 87,407 & 93,704 \\
\cline { 2 - 8 } & $\mathrm{pH}$ & 7 & 8.6 & 9.3 & 9.4 & 9.4 & 9.4 \\
\hline \multirow{4}{*}{5} & $\mathrm{NTU}$ & 170 & 79 & 42 & 25 & 17 & 10 \\
\cline { 2 - 8 } & $\%$ & 0 & 53,529 & 75,294 & 85,294 & 90,000 & 94,118 \\
\cline { 2 - 8 } & $\mathrm{pH}$ & 7 & 8.6 & 8.7 & 9.2 & 9.6 & 9.6 \\
\hline \multirow{3}{*}{6} & $\mathrm{NTU}$ & 179 & 82 & 49 & 32 & 19 & 14 \\
\cline { 2 - 8 } & $\%$ & 0 & 54,190 & 72,626 & 82,123 & 89,385 & 92,179 \\
\cline { 2 - 8 } & $\mathrm{pH}$ & 7 & 8.1 & 9.1 & 9.2 & 9.6 & 9.6 \\
\hline \multirow{2}{*}{7} & $\mathrm{NTU}$ & 450 & 230 & 152 & 89 & 40 & 18 \\
\cline { 2 - 8 } & $\%$ & 0 & 48,889 & 66,222 & 80,222 & 91,111 & 96,000 \\
\cline { 2 - 8 } & $\mathrm{pH}$ & 7 & 8.4 & 8.6 & 9.1 & 9.4 & 9.4 \\
\hline \multirow{3}{*}{8} & $\mathrm{NTU}$ & 441 & 213 & 128 & 65 & 23 & 14 \\
\cline { 2 - 8 } & $\%$ & 0 & 51,701 & 70,975 & 85,261 & 94,785 & 96,825 \\
\cline { 2 - 8 } & $\mathrm{pH}$ & 7 & 8.3 & 8.7 & 9.2 & 9.4 & 9.4 \\
\hline \multirow{4}{*}{9} & $\mathrm{NTU}$ & 268 & 112 & 71 & 33 & 14 & 8 \\
\cline { 2 - 8 } & $\%$ & 0 & 58,209 & 73,507 & 87,687 & 94,776 & 97,015 \\
\cline { 2 - 7 } & $\mathrm{pH}$ & 7 & 8.4 & 8.8 & 9.4 & 9.4 & 9.4 \\
\hline
\end{tabular}

Angka

persentase

penurunan kekeruhan

diperoleh dengan rumus :

\%removal $=\frac{N T U_{\text {awal }}-N T U_{t}}{N T U_{\text {awal }}} \times 100 \%$

IV HASIL DAN

PEMBAHASAN

Hasil pengamatan kekeruhan dan $\mathrm{pH}$ limbah selama proses berlangsung apat dilihat pada Tabel 2 berikut: 
Tabel 3. Level Faktor Desain Percobaan

\begin{tabular}{|c|c||c|c|}
\hline Level & $\begin{array}{c}\text { Kuat } \\
\text { Arus } \\
(\mathbf{A})\end{array}$ & $\begin{array}{c}\text { Konduktivitas } \\
(\mu \mathrm{s} / \mathrm{cm})\end{array}$ & $\begin{array}{c}\text { Jarak } \\
\text { antar } \\
\text { Elektroda } \\
(\mathbf{c m})\end{array}$ \\
\hline ke-1 & 0.2 & 2000 & 0.5 \\
\hline ke-2 & 0.3 & 2250 & 1 \\
\hline ke-3 & 0.4 & 2500 & 1.5 \\
\hline
\end{tabular}

Tabel 4. Data Hasil Analisis Taguchi terhadap Ratarata Persentase Penurunan Kekeruhan $(\% \mathrm{R})$ pada setiap Parameter

\begin{tabular}{|c|c|c|c||}
\hline \multirow{2}{*}{$\begin{array}{c}\text { Level } \\
\text { Faktor }\end{array}$} & $\begin{array}{c}\text { Kuat } \\
\text { Arus }\end{array}$ & $\begin{array}{c}\text { Konduk } \\
\text { tivitas }\end{array}$ & $\begin{array}{c}\text { Jarak } \\
\text { antar } \\
\text { Elektroda }\end{array}$ \\
\hline 1 & 92,065 & 93,627 & 93,393 \\
2 & 93,334 & 94,014 & 93,939 \\
3 & 96,613 & 94,372 & 94,68 \\
\hline Delta & 4,548 & 0,745 & 1,287 \\
\hline Rangking & 1 & 3 & 2 \\
\hline
\end{tabular}

Berdasarkan hasil analisis Taguchi [17], diketahui bahwa kuat arus memiliki nilai delta yang paling besar yaitu 4,548 dibandingkan jarak antar elektroda dengan delta 1,287 dan konduktivitas dengan delta 0,745. Nilai delta terbesar menunjukkan bahwa kuat arus merupakan faktor utama yang mempengaruhi persentase penurunan kekeruhan limbah tapioka.

\section{A. Pengaruh Arus Listrik Terhadap Penurunan Persentase Kekeruhan}

Kuat arus pada proses elektrokoagulasi memiliki pengaruh yang signifikan terhadap persen removal turbidity limbah cair tapioka. Berdasarkan Gambar 2 di bawah ini dapat dilihat bahwa peningkatan kuat arus dari 0,2 A menjadi 0,4 A menunjukkan persen removal turbidity meningkat tajam. Persen removal ini terus meningkat seiring dengan peningkatan kuat arus operasi. Persen removal tersebut akan meningkat sampai titik optimum sehingga akan diperoleh kuat arus optimum.

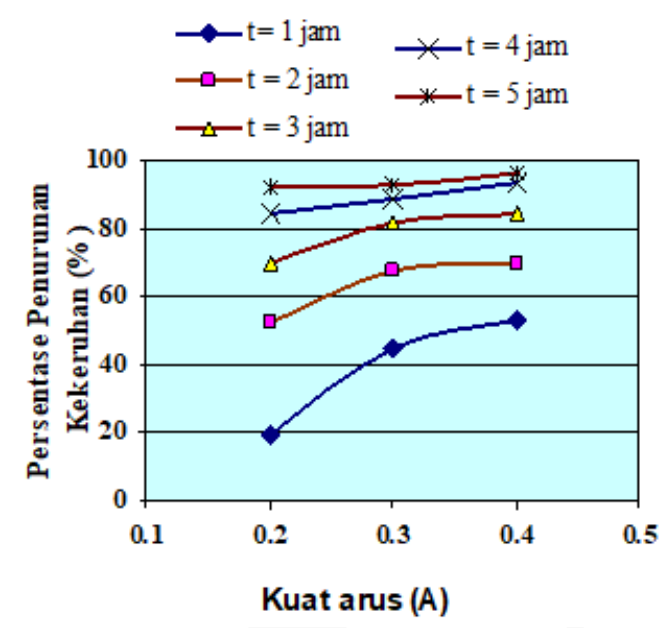

Gambar 2. Pengaruh Kuat Arus Terhadap RataRata Persentase Penurunan Kekeruhan

Reaksi oksidasi elektroda alumunium terjadi di kutub positif (anoda) dengan reaksi sebagai berikut [18]:

$$
\mathrm{Al} \rightarrow \mathrm{Al}^{+3}+3 \mathrm{e}^{-}
$$

Reaksi tersebut terjadi ketika sumber arus listrik searah dialirkan mengakibatkan elektroda alumunium yang digunakan luruh menghasilkan ion-ion $\mathrm{Al}^{+3}$. Ion-ion $\mathrm{Al}^{+3}$ kemudian berikatan dengan senyawa air yang terdapat dalam limbah dan membentuk senyawa $\mathrm{Al}(\mathrm{OH})_{3}$ dan ion $\mathrm{H}^{+}$.

$$
\mathrm{Al}^{+3}+3 \mathrm{H}_{2} \mathrm{O} \rightarrow \mathrm{Al}(\mathrm{OH})_{3}+3 \mathrm{H}^{+}
$$

Gambar 2 di atas dapat dilihat bahwa pada jam ke-1 untuk arus 0,2 A rata-rata persen penurunan kekeruhan (\%R) adalah 19,656\% sedangkan pada arus 0,4 A mencapai 54,933\%. Setelah proses elektrokoaguasi berlangsung selama 5 jam diperoleh persentase penurunan kekeruhan untuk arus 0,2 A yaitu 92,006\% dan pada arus 0,4 A diperoleh 96,613\%. Semakin besar arus yang digunakan maka laju pembentukan koagulan akan semakin meningkat dan akan semakin banyak partikelpartikel koloid yang dapat terikat oleh ion-ion alumunium. Berdasarkan analisis Taguchi terhadap rata-rata persentase penurunan 
kekeruhan diperoleh kuat arus optimal pada range kuat arus 0,2 - 0,4 A adalah 0,4 A. Pada kondisi ini didapatkan persen penurunan kekeruhan diatas $96 \%$.

Besarnya arus yang mengalir per luas permukaan elektroda didefinisikan sebagai densitas arus. Densitas arus pada proses elektrokoagulasi akan mempengaruhi waktu tinggal dan persentase removal kekeruhansuatu limbah cair. Gambar 3 memperlihatkan laju peningkatan persentase removal turbidity yang sangat signifikan. Hal ini terjadi karena reaksi yang terjadi adalah reaksi redoks yang tidak spontan tetapi reaksi ini memerlukan suatu pemicu agar reaksi reduksi oksidasi dapat berlangsung, dalam hal ini arus listrik sebagai pemicunya. Kecepatan pembentukan koagulan meningkat seiring dengan meningkatnya kuat arus. Pada saat yang bersamaan pembentukan gelembung gas hidrogen juga semakin cepat. Rejim aliran meningkat disebabkan pembentukan gelembung gas hidrogen sehingga proses hidrodinamika makin kuat yang akan menyebabkan meningkatnya flotasi flok-flok di dalam reaktor.

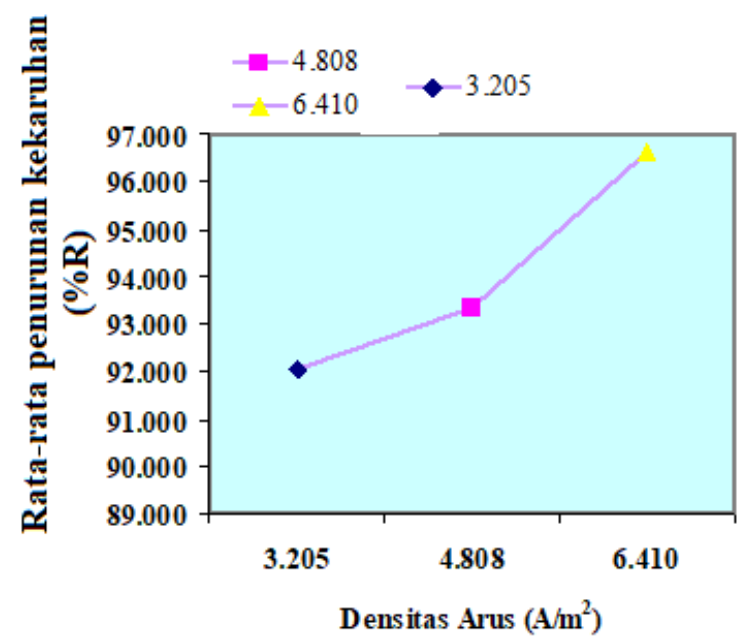

Gambar 3. Pengaruh Densitas Arus Terhadap \% Mean Removal kekeruhan (R\%)

\section{B. Pengaruh Konduktivitas Terhadap Persen Removal Turbidity}

Konduktivitas merupakan kemampuan suatu bahan untuk menghantarkan arus listrik. Untuk memperbesar konduktivitas maka ditambahkan garam $\mathrm{NaCl}$ ke dalam limbah cair. Tujuan penambahan $\mathrm{NaCl}$ bertujuan untuk mengurangi besarnya energi yang terpakai. Penambahan konduktivitas ini perlu dibatasi karena penambahan larutan garam yang berlebih akan menyebabkan tingginya biaya produksi dan memungkinkan terjadinya reaksi samping yang akan merugikan proses elektrokoagulasi. Oleh karena itu diperlukan nilai konduktivitas air limbah yang tepat agar proses koagulasi dapat berjalan secara sempurna.

Gambar 4 menggambarkan peningkatan persen penurunan kekeruhan limbah cair tapioka tiap jam pada level konduktivitas. Konduktivitas air limbah memiliki pengaruh terhadap R\%. Semakin besar konduktivitas air limbah maka R\% semakin besar. Konduktivitas limbah tapioka sebesar $2000 \mu \mathrm{S} / \mathrm{cm}$ setelah 1 jam memiliki R\% kekeruhan mencapai $29,717 \%$ sedangkan pada konduktivitas 2500 $\mu \mathrm{S} / \mathrm{cm}$ memiliki $\mathrm{R} \%$ kekeruhan sebesar $45,065 \%$. Setelah 5 jam beroperasi terjadi peningkatan persentase penurunan kekeruhan yaitu pada konduktivitas limbah tapioka sebesar $2000 \mu \mathrm{S} / \mathrm{cm}$ memiliki R\% kekeruhan mencapai 93,627\% dan pada konduktivitas $2500 \mu \mathrm{S} / \mathrm{cm}$ memiliki R\% kekeruhan mencapai 94,372\% Penurunan kekeruhan ini disebabkan karena adanya penambahan $\mathrm{NaCl}$ yang apabila terhidrolisis akan menghasilkan ion $\mathrm{Na}^{+}$. Semakin banyak $\mathrm{Na}^{+}$yang dihasilkan maka akan semakin banyak interaksi dengan ion negatif di dalam limbah sehingga akan menghasilkan banyak flok. Berdasarkan analisis Taguchi terhadap rata-rata persentase penurunan kekeruhan diperoleh konduktivitas optimal pada range konduktivitas 2000 - 2500 $\mu \mathrm{S} / \mathrm{cm}$ adalah $2500 \mu \mathrm{S} / \mathrm{cm}$. Pada kondisi ini didapatkan persen penurunan kekeruhan sebesar $94,372 \%$.

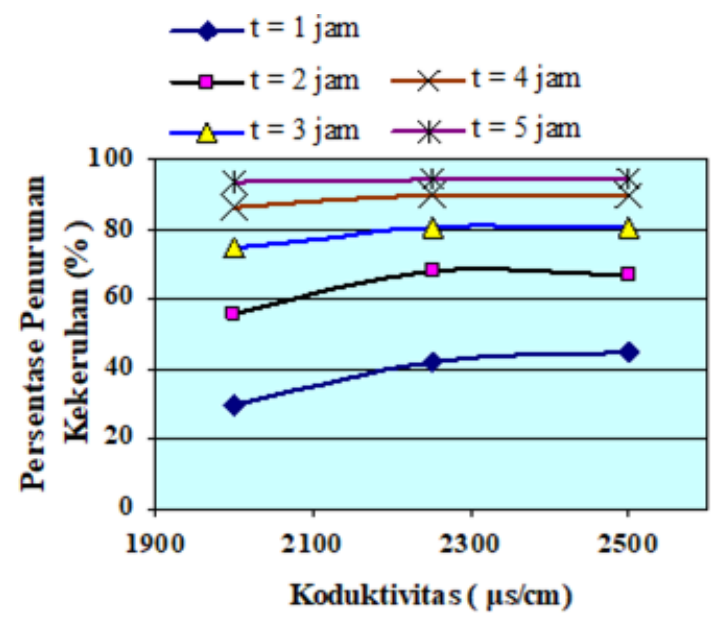

Gambar 4. Pengaruh Konduktivitas Terhadap Rata-Rata Persentase Penurunan Kekeruhan 


\section{Pengaruh Jarak Antar Elektroda Terhadap Persen Removal Turbidity}

Reaktor elektrokoagulasi yang digunakan berkapasitas 0,5 liter dengan dimensi 6 x 8,5 x $10,5 \mathrm{~cm}(\mathrm{p} \times 1 \times \mathrm{t})$ dan terbuat dari kaca $5 \mathrm{~mm}$. reactor ini didesain dengan menggunakan enam elektroda dengan dimensi 105 × 50 × 0,5 mm. Elektroda-elektroda tersebut disusun secara monopolar. Pemasangan elektroda membujur searah lebar reaktor (lebar reaktor $8,5 \mathrm{~cm}$ ).

Pada Gambar 5 diperlihatkan bahwa jarak antar antar elektroda tidak terlalu memiliki pengaruh yang signifikan terhadap persen penurunan kekeruhan untuk tiap rentang waktunya, meskipun berdasarkan hasil analisis desain taguchi pada akhir operasi jarak antar elekroda memiliki delta yang lebih besar dibanding pengaruh konduktivitas. Walaupun demikian penempatan elektroda yang baik akan membantu proses removal partikel-partikel koloid. Pada jarak antar elektroda $0,5 \mathrm{~cm}$ setelah 1 jam beroperasi diperoleh persentase penurunan kekeruhan sebesar 40,9188\% sedangkan pada jarak antar elektroda $1,5 \mathrm{~cm}$ diperoleh 42,7382\%.

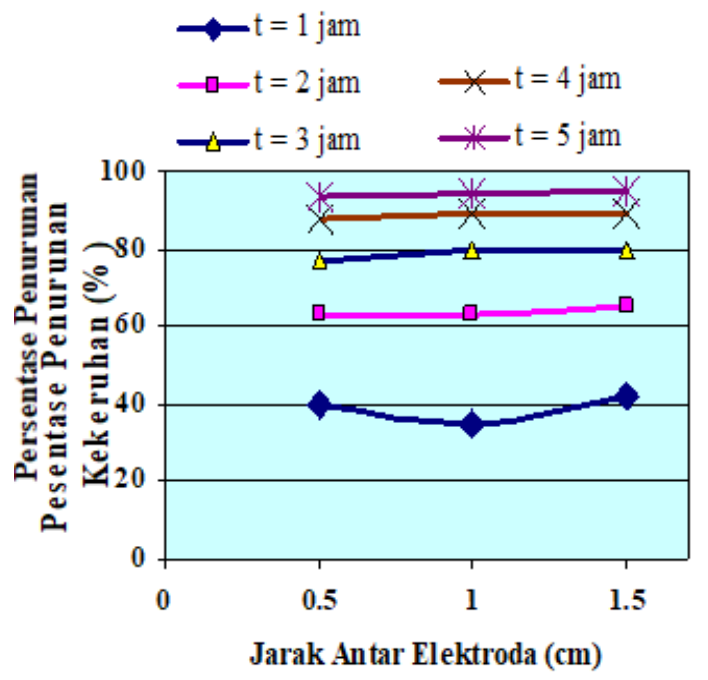

Gambar 5. Pengaruh Jarak antar Elektroda terhadap Rata-rata Persentase Penurunan Kekeruhan

Persentase penurunan kekeruhan semakin meningkat setelah 5 jam beroperasi yaitu pada jarak antar elektroda $0,5 \mathrm{~cm}$ diperoleh persentase penurunan kekeruhan sebesar 93,3935\% sedangkan pada jarak antar elektroda $1,5 \mathrm{~cm}$ persentase penurunan kekeruhan mencapai 94,6795 \%. Berdasarkan analisis Taguchi terhadap rata-rata persentase penurunan kekeruhan diperoleh jarak antar elektroda optimal pada range jarak antar elektroda $0,5-1,5 \mathrm{~cm}$ adalah $1,5 \mathrm{~cm}$. Pada kondisi ini didapatkan persen penurunan kekeruhan sebesar 94,6795\%.

Penempatan elektroda yang efektif memerlukan desain reaktor yang tepat agar semua aliran limbah dapat mengalir diantara kedua kutub yang berbeda. Distribusi aliran limbah yang mengalir diantara kedua kutub elektroda yaitu anoda dan katoda mempengaruhi proses koagulasi. Menurut Mameri dkk [19], koagulasi yang paling baik terjadi pada saat partikel-partikel koloid melewati dua sisi kutub elektroda yang berbeda. Gelembung-gelembung yang terbentuk di katoda akan membantu removal flok-flok yang terbentuk akibat interaksi partikel-partikel koloid limbah dengan kation $\mathrm{Al}^{3+}$ yang dihasilkan di anoda.

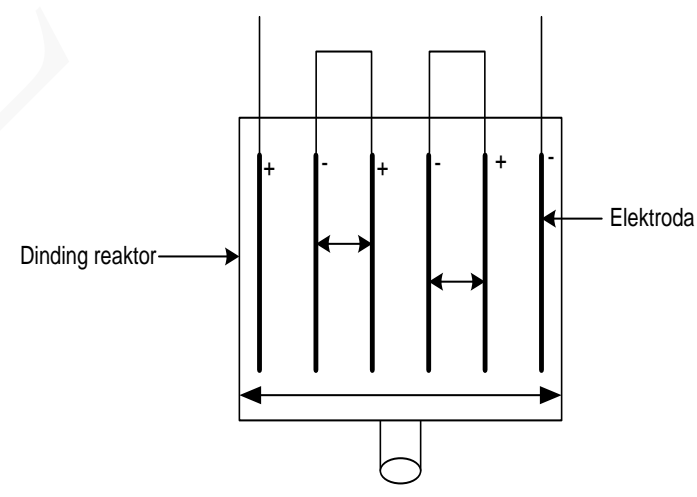

Gambar 6. Skematis Pemasangan Elektroda pada Reaktor Elektrokoagulasi

Jarak antar elektroda merupakan salah satu faktor yang mempengaruhi besarnya penggunaan energi. Penambahan jarak antar elektroda meningkatkan besarnya tegangan yang dibutuhkan karena besarnya tahanan yang diterima semakin besar. Resistansi limbah cair dapat diturunkan dengan penambahan garam ke dalam limbah tapioka agar konduktivitasnya meningkat. Pada pengoperasian dengan arus listrik yang tetap, penambahan jarak antar elektroda terlalu besar juga dapat mengurangi keefektifan proses elektrokoagulasi. Hal ini dikarenakan beban yang diterima pada tiap 
elektroda menjadi besar dan gelembunggelembung yang dihasilkan di katoda menjadi kurang efektif dalam membantu removal flokflok yang terbentuk. Pemasangan elektroda yang terlalu dekat dapat menyebabkan terjadinya hubungan singkat sehingga dapat merusak DC Power Supply yang digunakan.

\section{Perubahan pH Air Limbah selama proses elektrokoagulasi}

pH limbah cair tapioka yang keluar dari pabrik tapioka berkisar antara 5-6, dan $\mathrm{pH}$ limbah cair tapioka ini akan terus mengalami penurunan seiring dengan berjalannya waktu. Pada penelitian ini, sebelum diolah $\mathrm{pH}$ limbah cair tapioka dinaikkan terlebih dahulu menjadi 7 dengan penambahan $\mathrm{NaOH}$. Meskipun $\mathrm{pH}$ influent tidak memiliki pengaruh yang signifikan terhadap proses eletrokoagulasi pada rentang $3-10$.

Pada elektrokoagulasi limbah cair tapioka, limbah cair tapioka mengalami kenaikan $\mathrm{pH}$ selama proses berlangsung sehingga didapatkan $\mathrm{pH}$ effluent setelah 5 jam rata-rata diatas 9 seperti yang dapat kita lihat pada Tabel 2 . Kenaikan $\mathrm{pH}$ ini disebabkan oleh beberapa mekanisne yang terjadi selama proses elektrokoagulasi. $\mathrm{CO}_{2}$ yang berada di dalam limbah bisa terlepas dari limbah dan mengganggu gelembung-gelembung $\mathrm{H}_{2}$ sehingga menyebabkan $\mathrm{pH}$ meningkat (Chen, 2000). Adanya beberapa anion seperti $\mathrm{Cl}^{-}, \mathrm{SO}_{4}{ }^{-}$, $\mathrm{HSiO}_{4}^{-}, \mathrm{NO}_{3}{ }^{-}$dan lain-lain dapat menggantikan $\mathrm{OH}^{-}$pada $\mathrm{Al}(\mathrm{OH})_{3}$ yang akan menghasilkan $\mathrm{OH}^{-}$. Adanua ion $\mathrm{OH}^{-}$ini akan meningkatkan $\mathrm{pH}$ limbah. $\mathrm{OH}^{-}$dalam limbah dihasilkan dari disebabkan adanya reaksi hidrolisis air selama proses elektrokoagulasi dengan reaksi sebagai berikut [18]:

$\mathrm{H}_{2} \mathrm{O} \rightarrow \mathrm{H}_{2}+\mathrm{OH}^{-}$

$\mathrm{OH}^{-}$dari hasil hidrolisis air ini kemudian akan berikatan dengan $\mathrm{Al}^{3+}$ yang membentuk alumunium hidroksida. $\left(\mathrm{Al}(\mathrm{OH})_{\mathrm{n}}{ }^{\mathrm{x}}\right)$ dalam keadaan basa. Keadaan basa ini disebabkan banyaknya ion-ion $\mathrm{OH}^{-}$di dalam limbah.

\section{E. Elektrokoagulasi Limbah Cair Tapioka Pada Kondisi Optimal}

Kondisi optimal (ideal) proses elektrokoagulasi limbah cair tapioka dengan sistem batch recycle pada laju alir 9 liter/jam didapatkan dari analisa data hasil penelitian yang telah dilakukan yaitu sebagai berikut :

$\begin{array}{ll}\text { - Kuat arus } & : 0.4 \mathrm{~A} \\ \text { - Konduktivitas } & : 2500 \mu \mathrm{S} / \mathrm{cm} \\ \text { - Jarak antar elektroda } & : 1,5 \mathrm{~cm} \\ \text { - pH } & : 7 \\ \text { - Waktu operasi } & : 5 \mathrm{jam}\end{array}$

Analisa hasil percobaan yang telah dilakukan berdasarkan pada kondisi optimal diatas dapat dilihat pada Tabel 5. Analisanya meliputi Total Suspended Solid (TSS), dan turbidity. Pada analisa TSS, sebelum diolah TSS limbah cair tapioka sebesar $375 \mathrm{mg} / \mathrm{l}$ dan setelah diolah terjadi penurunan yang sangat signifikan yaitu menjadi $11 \mathrm{mg} / \mathrm{l}$, sehingga besarnya persentase removal TSS adalah 97,067\%. Sedangkan hasil analisa turbidity didapatkan 17 NTU, yang sebelum diolah besarnya turbidity sebesar 613 NTU. Dari nilai akhir dan awal turbidity tersebut, maka besarnya persentase removal turbidity sebesar 97,226\%. Standar maximal TSS dan kekeruhan yang dibolehkan adalah 100 mg/l sedangkan kekeruhan 100 NTU

Tabel 5 Hasil Analisa Pengolahan Limbah Cair Tapioka pada Kondisi Optimum Berdasarkan analisis Desain

\begin{tabular}{|c|c|c|c|c|}
\hline $\begin{array}{c}\text { Wak } \\
\text { tu } \\
\text { opera } \\
\text { si } \\
\text { (jam) }\end{array}$ & $\begin{array}{c}\text { Turbi } \\
\text { ditas } \\
\text { (NTU) }\end{array}$ & $\begin{array}{c}\text { Penu } \\
\text { runan } \\
\text { NTU, } \\
\%\end{array}$ & $\begin{array}{c}\text { TSS } \\
\text { mg/l }\end{array}$ & $\begin{array}{c}\text { Penuru } \\
\text { nan } \\
\text { TSS, \% }\end{array}$ \\
\hline 0 & 613 & $0 \%$ & 375 & 0 \\
\hline 1 & 423 & $30.99 \%$ & 200 & $29.86 \%$ \\
\hline 2 & 230 & $62.48 \%$ & 112 & $70.13 \%$ \\
\hline 3 & 167 & $72.75 \%$ & 84 & $77,60 \%$ \\
\hline 4 & 62 & $89.88 \%$ & 50 & $86.66 \%$ \\
\hline 5 & 17 & $97.22 \%$ & 11 & $97.06 \%$ \\
\hline
\end{tabular}

Dari Tabel 5 diatas dapat dilihat adanya peningkatan persentase penurunan kekeruhan tiap jamnya. Pada satu jam operasi didapatkan persentase penurunan kekeruhan sebesar $30,995 \%$ dan setelah lima jam terjadi peningkatan persentase penurunan kekeruhan mencapai $97,227 \%$. 


\section{PENUTUP}

Limbah cair industry tapioca telah berhasil diolah melalui proses elektrokoagulasi menggunakan elektroda aluminium yang disusun secara monopolar. Adapun faktorfaktor yang mempengaruhi keberhasilan proses elektrogulasi dalam penurunan tingkat kekeruhan seperti kuat arus, konduktivitas dan jarak antar elektroda diobservasi dalam penelitian ini. Hasil penelitian Menunjukan bahwa kuat arus merupakan faktor utama yang mempengaruhi persentase penurunan kekeruhan limbah cair tapioka. Kondisi optimum dicapai pada Kuat arus: 0.4 A: Konduktivitas: $2500 \mu \mathrm{S} / \mathrm{cm}$, jarak antar elektroda: 1,5 cm dengan waktu operasi 5 jam. Pada kpndisi optimum tingkat penurunan kekeruhan mencapai $97.227 \%$.

\section{UCAPAN TERIMA KASIH}

Penulis mengucapkan terimakasih atas terselenggaranya penelitian ini berkat bantuan dana penelitian melalui Dana Penerimaan Negara Bukan Pajak (PNBP) 2005 Universitas Lampung.

\section{REFERENSI}

[1]Irawan. Pengaruh jenis kapang amilolitik dan konsentrasi pati terhadap pembentukan pelet dan tingkat penurunan kadar pati media cair sintetis. Skripsi. Universitas Lampung. Bandar Lampung. 1998.

[2]Djarwati, I. Fauzi, dan Sukani. Pengolahan air limbah industri tapioka secara kimia fisika. Laporan penelitian. Departemen Perindustrian RI. Semarang 1993.

[3]E. Suparmi, Tinjauan kualitas limbah cair tapioka pada PT Budi Acid Jaya. Laporan PKL. Akademi Kesehatan Lampung. Lampung 1997.

[4] M.A. Oliveira, M.R. Edson, J. Nozaki, 2001. Biological treatment of wastewater from cassava meal industry. Environmental Research Section, vol. 85, pp.177-183, 1993.

[5]Nurhasan. Buku panduan penanggulangan limbah cair industri kecil tapioka. Yayasan Bina Karya Lestari. Semarang. 1993.

[6] Keputusan Mentri Negara Lingkungan Hidup No.: Kep-51/MENLH/10/1995 Tentang Baku Mutu Air Limbah Bagi Kawasan Industri.

[7]B. Triwiyono, Kajian proses pendahuluan ubikayu segar dan tepung gaplek untuk media fermentasi etanol dengan enzim diabase K-27.
Laporan Kegiatan UPT-EGP. BPPT. Sulusuban. B. 1990.

[8] C.W.K.Chow, J.A. Leeuwe, V.M. Drikas, R.Fabris, K.M. Spark, D.W. Page, The impact of the character of natural organic matter in conventional treatment with alum. Water Science and Tecnology, vol. 40(9), pp. 97-104, 1999.

[9] B. Eikebrokk, Coagulation-direct filtration of soft, low alcalinity humic water. Water Science Tecnology, vol. 40(9) pp. 55-62, 1999..

[10] W. Viesman, dan M.J. Hammer. Water supply and pollution control. Addison Wesley. Florida. M.J. 1998.

[11] S.G.J. Heijman, A.M.V. Passen, W.G.J.V.D. Meer, R. Hopman, R. Adsortive removal of natural organic matter during drinking water treatment. Water Science and technology, vol. 40(9), pp. 183-190, 1999.

[12] M. Alborzfar,G. Johnsson, C. Gron, Removal of natural organic matter from two type of humic ground waters by nonfiltration. Water Research, vol. 32(10), pp. 2893-2994. 1998

[13] X.M. Chen, G.I.I. Chen, P.L.Yue, Investigation on the voltage of electrocoagulation. Chemical Engineering Science, vol.57. pp. 2449-2455.

[14] L. Joffe,L., dan L. Knieper, Electrocoagulation: technology quickly removes barium, total suspended solids from a water-retention pond for fractions of a cent per gallon, Industrial Waste Water, vol. 20, pp. 0110, 2000,

[15] X.M. Chen, G.I.I. Chen, P.L.Yue, Separation of pollutants from restaurant wastewater by electrocoagulation, Separation and Purification Technology, vol.19, pp. 65-76, 2000,

[16] J.Q. Jiang, N. Graham, C. Andre, G.H. Kelsall, N. Brandon, Laboratory study of electrocoagulation-flotation fro water treatment, Water Research, vol. 36, pp. 4064-4078,2002

[17] P.B. Tapan, Taguchi methods explainedPractical Steps to Robust Design Prentice Hall of India New Delhi-1993.

[18] M.Y.A. Mollah, R Schennach, J.R., Parga, C.L Cocke, Electrocoagulation (EC) - science and applications, Journal of Hazardous Materials, B84, pp. 29-41, 2000.

[19] N. Mameri, I.I. lounici, D. Belhocine, I.I. Grib, D.L. Piron, Y. Yalhiat, Defluoridation of sahara water by small plant electrocoagulation using bipolar alumunium electrodes. Separation and Purification Technology, vol.24. pp. 113-119, 2001 